\title{
Erratum to: Voices of the Internet of Things: An Exploration of Multiple Voice Effects in Smart Homes
}

\author{
Yohan Moon ${ }^{1}$, Ki Joon Kim² ${ }^{2}$ and Dong-Hee $\operatorname{Shin}^{3(\bowtie)}$ \\ ${ }^{1}$ Department of Interaction Science, Chung-Ang University, Seoul, South Korea \\ ttattang@skku.edu \\ 2 Department of Media and Communication, City University of Hong Kong, \\ Hong Kong, China \\ stand4good@gmail.com \\ ${ }^{3}$ School of Media and Communication, Chung-Ang University, \\ Seoul, South Korea \\ dshin1030@cau.ac.kr
}

\section{Erratum to:}

Chapter 25 in: N. Streitz and P. Markopoulos (Eds.) Distributed, Ambient and Pervasive Interactions DOI: 10.1007/978-3-319-39862-4_25

The initially published affiliation of the author Shin, D., was incorrect. The correct affiliation is as follows: School of Media and Communication, Chung-Ang University. 